\title{
Management of Soft Tissue Injuries Associated with Tibial Plateau Fractures
}

\author{
Joseph Borrelli, Jr., MD ${ }^{1}$ \\ ${ }^{1}$ Department of Orthopedic Surgery, Texas Health Arlington Memorial \\ Hospital, Arlington, Texas \\ Address for correspondence Joseph Borrelli, Jr., MD, 902 West Randol \\ Mill Road, Suite 120, Arlington, TX 76012 \\ (e-mail: JosephBorrelli@texashealth.org).
}

J Knee Surg 2014;27:5-10.

\begin{abstract}
Keywords

- tibial plateau fracture

- soft tissue injury

- fracture blister

Tibial plateau fractures or knee fracture-dislocations often result from trauma or sporting injuries. Given the subcutaneous position of the knee and upper tibia, without much intervening soft tissue, any such injury can be associated with significant soft tissue damage. Thus, consideration of the degree of soft tissue injury must be part of the treatment plan. Specific management decisions regarding blisters, open wounds, and compartment syndrome are discussed, as well as the timing of surgery, role of provisional external fixation, and placement of incisions for definitive internal fixation.
\end{abstract}

Successful management of the soft tissues about the knee following a high-energy knee injury or tibial plateau fracture is paramount to a good outcome. The paucity of subcutaneous tissue about the knee in most patients increases the susceptibility of the soft tissues of the proximal tibia to injury by both external trauma and from within (due to displacement of bone fragments.) This increases the risk of complications following the treatment of high-energy proximal tibia fractures. This review will highlight the unique aspects of the soft tissues covering the proximal tibia and how they are commonly injured in the setting of a high-energy proximal tibia fracture. In addition, we will discuss techniques developed over time to avoid additional soft tissue injury during the course of treatment and subsequently the disastrous complications associated with wound dehiscence and deep infection that have historically plagued the treatment of high-energy proximal tibia fractures. ${ }^{1-8}$

The medial aspect of the proximal tibia is essentially covered by skin and subcutaneous tissue and the attachment of the sartorius, gracilis, and semitendinosis muscles. The most proximal aspect of the lateral tibia is also only covered by skin and subcutaneous tissue as well as the attachment of the iliotibial band at Gerdy tubercle. Slightly more distally, the proximal tibia is covered by the origins of the anterior compartment musculature including the anterior tibialis, extensor hallucis longus, and the extensor digitorum muscles. The peroneal nerve wraps around the proximal fibula traveling from the posterior lateral aspect of the knee into the anterior compartment of the leg. In contrast, the posterior aspect of the proximal tibia enjoys a robust soft tissue covering including the proximal aspect of the gastrocnemius which originates on the distal femur as well as the origins of the muscles that comprise the superficial and deep compartments of the posterior compartment of the leg. 9,10

\section{Mechanism of Injury}

One of the most common and often the most severe injury mechanism that leads to compromised soft tissues of the proximal tibia occurs in the form of a direct impact. Historically, this mechanism has been seen in pedestrians struck by motor vehicles, where the bumper of the car comes into direct contact with the proximal tibia causing the fracture as well as direct injury to the surrounding soft tissues. The amount of energy absorbed by the proximal tibia and surrounding soft tissues at the time of impact is substantial and enough to cause considerable fracturing and comminution of the tibia and severe soft tissue injury. Similar soft tissue injury and proximal tibial fracture patterns are also commonly seen in motorcycle crashes, industrial accidents, and loading dock injuries where the worker's leg is caught between the advancing truck or its lift and the loading dock.

The soft tissues surrounding the proximal tibia can also be indirectly injured in association with high-energy proximal tibia fractures that result from "indirect" mechanisms. Indirect mechanisms include axial compression type fractures received

November 9, 2013

accepted

November 12, 2013

published online

December 19, 2013
Copyright (c) 2014 by Thieme Medical Publishers, Inc., 333 Seventh Avenue, New York, NY 10001, USA. Tel: +1(212) 584-4662.
DOI http://dx.doi.org/ 10.1055/s-0033-1363546. ISSN 1538-8506. 
that occur as a result of a fall, or violent twisting or forceful angular mechanisms that are often seen as a result of highenergy sporting injuries (i.e., skiing, football, rugby, etc.) In these types of injuries, the soft tissues are injured as a result the energy dissipated by creation of the underlying fracture fragments and the subsequent swelling and inflammation that follows. Quantifying the amount of energy absorbed by the bone and soft tissues at the time of injury has been attempted by measuring fracture fragment displacement and fracture fragment volume. ${ }^{11,12}$

\section{Classification of Soft Tissue Injury}

At times, the mechanism of injury and the amount of energy absorbed by the bone and soft tissues is sufficient to cause disruption of the soft tissue envelope resulting in an open fracture. In these cases, management of the soft tissues includes cleansing of the open wound and restoring the circumferential soft tissue coverage of the tibia while mitigating any further injury to the soft tissue envelope. Gustilo and Anderson originally proposed a classification of open tibial shaft fractures in the 1970s that is also commonly used to describe open tibial plateau fractures. ${ }^{13,14}$ Oestern and Tscherne developed a classification system designed to describe closed soft tissue injuries, in the setting of a tibial shaft fracture. ${ }^{15}$ These well-known and widely used classification systems provide common language for describing the soft

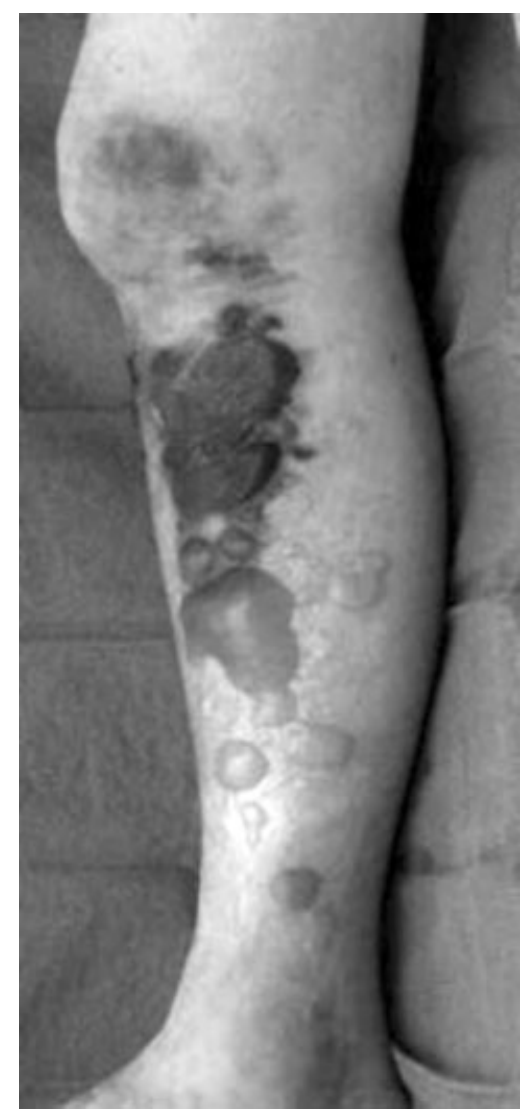

Fig. 1 Fluid and blood filled blisters of the proximal and middle portions of the leg following a high-energy tibial plateau fracture. tissue injuries in both open and closed fractures, allowing for more precise documentation, and the ability to compare like groups of patients with improved accuracy. In addition, the use of classification systems helps physicians better appreciate the degree of soft tissue injury and may guide treatment and allow prognostication at an earlier stage.

\section{Common Pathway of Soft Tissue Injury}

The soft tissue trauma associated with high-energy tibial plateau fractures is generally sufficient to incite soft tissue edema and inflammation that leads to local venous compromise, dermal hypoxia, and additional soft tissue injury. ${ }^{16,17}$ This additional soft tissue compromise commonly leads to blistering of the skin and in some cases dermal and even muscle necrosis (-Fig. 1). ${ }^{18,19}$ Although little can be done to prevent this cascade from beginning, preventing further soft tissue injury while waiting to repair the fracture is essential. Careful preoperative soft tissue management is important in avoiding additional injury and facilitating soft tissue healing and recovery. Immobilization of the knee in this setting and employing means to decrease the inflammatory response (cryotherapy) are two of the most common means that physicians use in the acute treatment of soft tissue injuries. ${ }^{20-24}$

Well-padded long leg splints are generally sufficient to immobilize the fractures but require circumferential dressings that prevent easy access to the soft tissues beneath. Temporary placement of knee-spanning external fixators are indicated for those fractures which are axially unstable and can be used to reapproximate the fracture fragments by the process of ligamentotaxis and obviate the need for circumferential dressings (-Figs. 2-5). These spanning external fixators are placed in the operating room and greatly aid in patient comfort. In many cases, once the spanning external fixator has been applied, patients can be mobilized and taught to ambulate with crutches or a walker while waiting for the soft tissues to fully recover. ${ }^{25}$

There are several different configurations that knee-spanning external fixator constructs can take. The keys to a stable frame include the use of robust half pins $(4.5-5.0 \mathrm{~mm}$

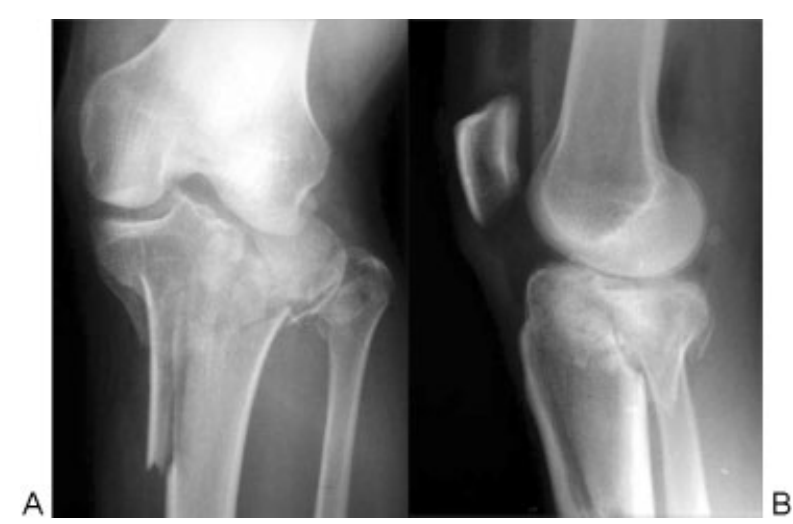

Fig. 2 (A, B) Anterior-posterior and lateral radiographs of axially unstable, displaced, high-energy bicondylar tibial plateau fracture (AO/OTA 41-C) associated with significant swelling and blistering of the surrounding soft tissues. 


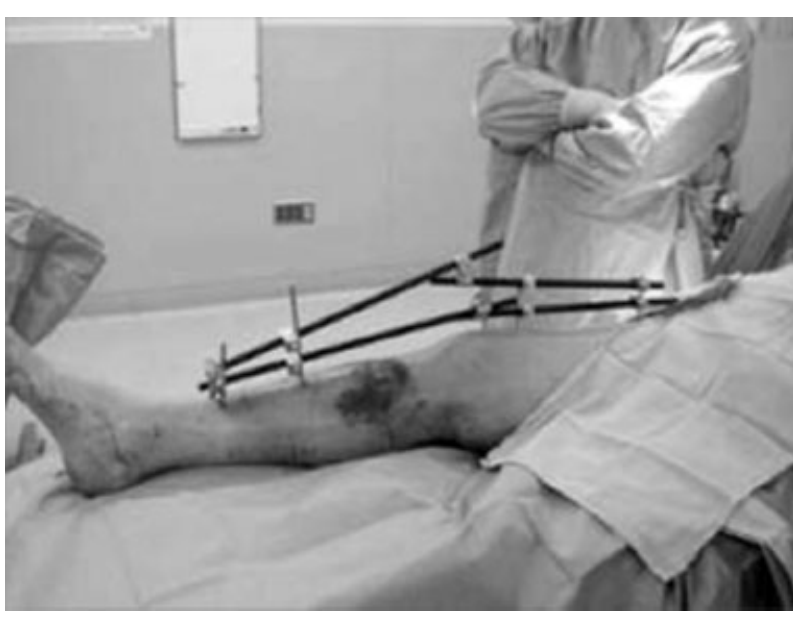

Fig. 3 A spanning multiplanar external fixator has been applied to provide stabilization of the limb and reapproximation of the surrounding soft tissues.

thickness), double stacking the connecting bars, and placement of the bars in at least two planes relative to the knee. To minimize the risk of contaminating the fracture, it is important to keep the pins out of the path of future skin incisions and to avoid placing the pins into the fracture hematoma. Avoiding the hematoma limits contamination of the fracture site and decreases drainage from the pin sites. The use of spanning external fixators before definitive open reduction and internal fixation (ORIF) of proximal tibia and distal tibia fractures has not been shown to increase the risk of infection. ${ }^{26,27}$

A popular external fixator frame configuration includes placing two half pins in the anterolateral aspect of the femoral shaft (between the rectus femoris and the vastus lateralis muscles) or directly through the rectus femoris and the vastus intermedius in the mid-sagittal plane. These pins should engage the endosteum of the far cortex or completely penetrate the far cortex to assure secure purchase. The tibial pins (at least two) should be placed in the mid-sagittal plane of the tibial shaft, a half finger breath medial to the tibial crest.

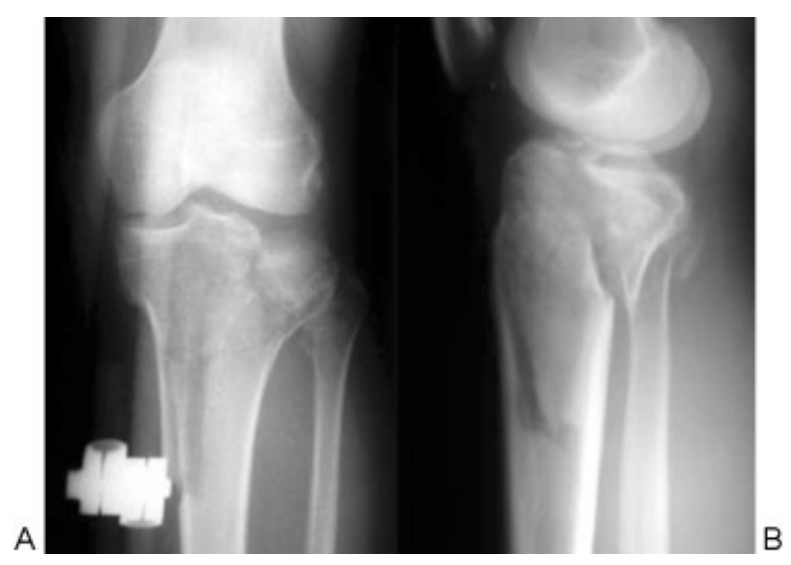

Fig. 4 (A, B) Anterior-posterior and lateral radiographs after application of a spanning external fixator demonstrates restoration of limb alignment and reapproximation of the fracture fragments through the process of ligamentotaxis.

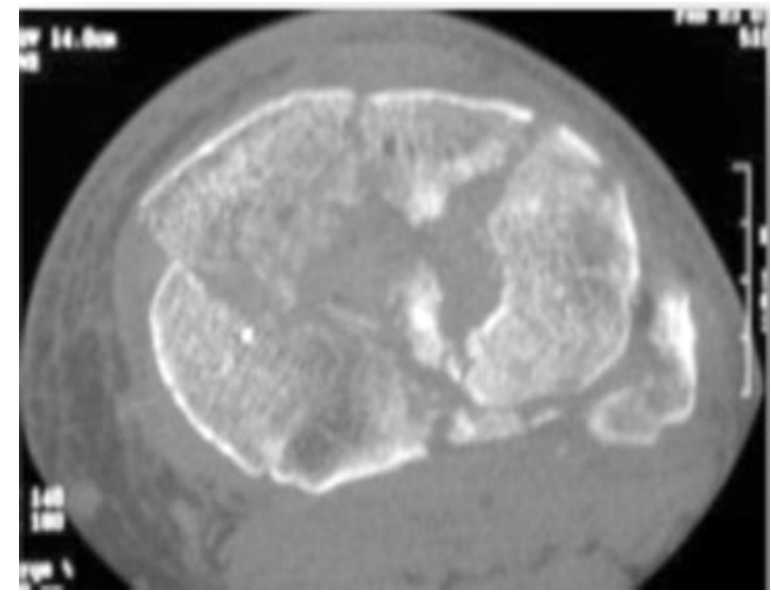

Fig. 5 Representative computed tomography image of a high-energy displaced tibial plateau fracture performed after the application of a spanning external fixator.

These pins should be placed as suggested above either engaging the endosteum of the far cortex or through the far cortex. Radiolucent carbon fiber rods should be used to connect these pins to facilitate subsequent X-rays and computed tomography scans. These bars should be configured in the mid-sagittal plane to resist flexion and extension forces and in the coronal plane to resist varus/valgus forces (-Fig. 3 ). Before tightening the pin to bar clamps, axial traction should be applied to the leg to reapproximate the fracture fragments and to restore normal axial alignment of the limb; this also an ideal time to reposition any fracture fragments that may be impinging upon the soft tissue from within.

On the basis of the extent of the soft tissue injury and degree of contamination and patient-related factors, open wounds can either be irrigated and debrided and closed with or without reduction and internal fixation of the articular fragments, or if the wounds are considered clean and viable definitive ORIF can be performed acutely. ${ }^{28}$ If ORIF is not performed acutely consideration should be given in the setting of an open tibial plateau fracture for the placement of a spanning external fixator as described above.

There are multiple ways to manage the fracture blisters (-Fig. 1). Many surgeons will maintain the integrity of the blisters while waiting for the soft tissues to recover if they are intact. Generally, the blisters are covered with a nonadherent dressing beneath the splint or dressings. If the blisters have been disrupted, many surgeons will unroof them completely, usually in the operating room, and cover the raw blister bed with a nonadherent dressing. The author has been using a betadine impregnated dressing (Xeroform Gauze, PSS World Medical, Jacksonville, FL) as described for the management of fracture blisters pre- and postoperatively.

Intraoperative soft tissue management is also important to minimize additional soft tissue injury. Choosing the correct timing for definitive treatment of these high-energy fractures is critical. In many cases, waiting 7 to 10 days is sufficient to allow time for the soft tissues to recover and regain some of their normal turgor and for previously open wounds to heal. Incisions 
should be planned to minimize excessive soft tissue stripping. Generally, displaced, high-energy, bicondylar tibial plateau fractures are treated with two primary incisions. The anterolateral, "hockey stick" or "lazy s"-shaped incision is used to address the displaced lateral tibial plateau and to attach the articular block to the shaft of the tibia, while a medial incision, half finger breath posterior to the posteromedial tibia, is used to address the medial and posteromedial tibial plateau fragments. In each case, gentle retraction of the injured soft tissue should be intermittently applied to facilitate exposure of the fracture. It is generally accepted that incisions can pass through previous fracture blister sites but many of us will avoid doing this if doing so does not compromise our exposure. Atraumatic layered closure of the deep fascia, subcutaneous tissue, and skin should be performed while minimizing further soft tissue injury.

Postoperative soft tissue management includes continued management of blisters that have not fully healed and avoidance of restrictive dressings that could further compromise the soft tissues from the expected postoperative swelling. In certain situations negative pressure dressing may be applied to the medial and lateral incisions to facilitate wound drainage and speed healing of the incisions previously made through these traumatized soft tissues. In addition, sequential compression devices and/or foot pumps can also be used to further facilitate the resolution of the limb edema as well as help prevent the development of deep venous thrombosis.

\section{Summary}

Significant soft tissue injuries generally accompany high-energy tibial plateau fractures. The successful management of the soft tissues surrounding the proximal tibia in the pre-, intra-, and postoperative periods is nearly as important as the accurate and thoughtful treatment of the displaced fracture. Swelling, fracture blisters, and the presence of open wounds need to be treated aggressively and often benefit from the application of a temporary spanning external fixator to stabilize the fracture and knee and reapproximate the fracture fragments through the process of ligamentotaxis. Cryotherapy and the avoidance of additional surgical insults will decrease the inflammatory response and limit additional soft tissue injury. Surgeons treating these injuries must be patient and embark on operative reduction and internal fixation only when the soft tissues have recovered sufficiently to tolerate an additional insult. Single, midline incision which requires the development of large medial and lateral soft tissue flaps should be avoided at all costs and surgeons must become familiar with the posteromedial incisions to address the medial and if present the posteromedial fracture fragments. Closure of the incisions must be done with attention to detail and meticulously and consideration should be given to the use of negative pressure dressings in the immediate postoperative period.

\section{References}

1 Barei DP, Nork SE, Mills WJ, Henley MB, Benirschke SK. Complications associated with internal fixation of high-energy bicondylar tibial plateau fractures utilizing a two-incision technique. J Orthop Trauma 2004;18(10):649-657
2 Honkonen SE. Degenerative arthritis after tibial plateau fractures. J Orthop Trauma 1995;9(4):273-277

3 Lachiewicz PF, Funcik T. Factors influencing the results of open reduction and internal fixation of tibial plateau fractures. Clin Orthop Relat Res 1990;(259):210-215

4 Lansinger O, Bergman B, Körner L, Andersson GB. Tibial condylar fractures. A twenty-year follow-up. J Bone Joint Surg Am 1986; 68(1):13-19

5 Moore TM, Patzakis MJ, Harvey JP. Tibial plateau fractures: definition, demographics, treatment rationale, and long-term results of closed traction management or operative reduction. J Orthop Trauma 1987;1(2):97-119

6 Papagelopoulos PJ, Partsinevelos AA, Themistocleous GS, Mavrogenis AF, Korres DS, Soucacos PN. Complications after tibia plateau fracture surgery. Injury 2006;37(6):475-484

7 Rademakers MV, Kerkhoffs GM, Sierevelt IN, Raaymakers EL, Marti RK. Operative treatment of 109 tibial plateau fractures: five- to $27-$ year follow-up results. J Orthop Trauma 2007;21(1):5-10

8 Scotland T, Wardlaw D. The use of cast-bracing as treatment for fractures of the tibial plateau. J Bone Joint Surg Br 1981;63B(4): 575-578

9 Warren LF, Marshall JL. The supporting structures and layers on the medial side of the knee: an anatomical analysis. J Bone Joint Surg Am 1979;61(1):56-62

10 Seebacher JR, Inglis AE, Marshall JL, Warren RF. The structure of the posterolateral aspect of the knee. J Bone Joint Surg Am 1982;64(4): 536-541

11 Thomas TP, Anderson DD, Mosqueda TV, et al. Objective CT-based metrics of articular fracture severity to assess risk for posttraumatic osteoarthritis. J Orthop Trauma 2010;24(12):764-769

12 Anderson DD, Mosqueda T, Thomas T, Hermanson EL, Brown TD, Marsh JL. Quantifying tibial plafond fracture severity: absorbed energy and fragment displacement agree with clinical rank ordering. J Orthop Res 2008;26(8):1046-1052

13 Gustilo RB, Anderson JT. Prevention of infection in the treatment of one thousand and twenty-five open fractures of long bones: retrospective and prospective analyses. J Bone Joint Surg Am 1976;58(4):453-458

14 Gustilo RB, Mendoza RM, Williams DN. Problems in the management of type III (severe) open fractures: a new classification of type III open fractures. J Trauma 1984;24(8):742-746

15 Oestern HJ, Tscherne H. Pathophysiology and classification of soft tissue injuries associated with fractures. In: Tscherne H, Gotzen L, eds. (Telger TC, Trans.). Fractures with Soft Tissues Injuries (German). Berlin, Germany: Springer-Verlag; 1984:1-9

16 Schaser KD, Vollmar B, Menger MD, et al. In vivo analysis of microcirculation following closed soft-tissue injury. J Orthop Res 1999;17(5):678-685

17 Sudkamp NP. Soft-tissue injury: pathophysiology and its influence on fracture management. In: Reudi TP, Murphy WM, eds. AO Principles of Fracture Management. Stuttgart, Germany: Thieme Verlag; 2000:59-77

18 Giordano CP, Koval KJ, Zuckerman JD, Desai P. Fracture blisters. Clin Orthop Relat Res 1994;307(307):214-221

19 Giordano CP, Koval KJ. Treatment of fracture blisters: a prospective study of 53 cases. J Orthop Trauma 1995;9(2):171-176

20 Gardner AMN, Fox RH. The venous footpump: influence on tissue perfusion and prevention of venous thrombosis. Ann Rheum Dis 1992;51(10):1173-1178

21 Gardner AMN, Fox RH, Lawrence C, Bunker TD, Ling RS, MacEachern AG. Reduction of post-traumatic swelling and compartment pressure by impulse compression of the foot. J Bone Joint Surg $\mathrm{Br}$ 1990;72(5):810-815

22 McMaster WC, Liddle S. Cryotherapy influence on posttraumatic limb edema. Clin Orthop Relat Res 1980;150(150):283-287

23 Webb JM, Williams D, Ivory JP, Day S, Williamson DM. The use of cold compression dressings after total knee replacement: a randomized controlled trial. Orthopedics 1998;21(1):59-61 
24 Healy WL, Seidman J, Pfeifer BA, Brown DG. Cold compressive dressing after total knee arthroplasty. Clin Orthop Relat Res 1994; 299(299):143-146

25 Anglen JO, Aleto T. Temporary transarticular external fixation of the knee and ankle. J Orthop Trauma 1998;12(6):431-434

26 Laible C, Earl-Royal E, Davidovitch R, Walsh M, Egol KA. Infection after spanning external fixation for high-energy tibial plateau fractures: is pin site-plate overlap a problem? J Orthop Trauma 2012;26(2):92-97
27 Egol KA, Tejwani NC, Capla EL, Wolinsky PL, Koval KJ. Staged management of high-energy proximal tibia fractures (OTA types 41): the results of a prospective, standardized protocol. J Orthop Trauma 2005;19(7):448-455, discussion 456

28 Benirschke SK, Agnew SG, Mayo KA, Santoro VM, Henley MB. Immediate internal fixation of open, complex tibial plateau fractures: treatment by a standard protocol. J Orthop Trauma 1992; 6(1):78-86 